\title{
Cuates Agazapados y Otros Temas: Unas Palabras con Gustavo Sainz
}

Aparece en el México de los sesenta una figura equívoca: joven, ojos grandes, cara infantil, Gustavo Sainz parece demasiado tímido para ser novelista. Si la aparición de Gazapo en 1965 desmiente esa posibilidad, en 1969 Obsesivos días circulares la destruye. Escritor, crítico, profesor y director de revista, Sainz es una de las figuras más importantes en México y fuera de ese país. Aunque se debe su fama principalmente a sus novelas, ha publicado dos autobiografías, o conatos de autobiografías, numerosos artículos de crítica literaria y varios cuentos sueltos.

Gazapo es el relato confesional de un adolescente que vive en la capital y que es arquitecto de una complicada red de engaños y mentiras. Introduciendo la grabadora omnipresente como otro plano narrativo en su novela, Sainz penetra la infracultura adolescente que él mismo, posiblemente hacía poco, había vivido en el Distrito Federal. Llamarla una novela autobiográfica sería decir poco o nada. Lo importante es el auténtico estudio del pícaro urbano que se produce en la novela. La traduccion de la obra ha sido recibida con una buena crítica en español y en francés, italiano e inglés.

Obsesivos dias circulares no alcanza la recepción crítica ni la difusión pública que Gazapo, tal vez porque sea una novela más complicada, una novela que exige una labor más ardua por parte del lector. Joyceana o lezamalimesca ( ¿lezamalimefia?) en su visión, ésta es una obra densa, difícil, casi impenetrable por el lector medio. El narrador (¿una posible máscara de Sainz?), que es el eje de la obra, da la casualidad, es también lector de Ulysses. Se presenta al lector el bajo mundo de México a través de una serie de crimenes, asesinatos, episodios sexuales y otras delicias. Imaginación, invención y conciencia narrativa son las palabras que mejor describen la obra.

Desde 1969, Sainz ha viajado, ha madurado, en fin, ha vivido mucho. Después de tantas publicaciones y tomando en cuenta su edad, no se le puede considerar ya como joven. Tiene 34 años (bien contados, me imagino) y se dedica a la publicación de una revista, Siete, y a la cátedra de literatura que ocupa en la universidad. Sigue leyendo y sigue escribiendo. Actualmente está trabajando en una novela, Paseo en trapecio, de la cual han aparecido dos fragmentos en revistas mexicanas. Es en esta obra donde más se puede notar su maduración literaria. La gran preocupación por el lenguaje es evidente, dejando sentirse en ella la estampa de sus lecturas de Cabrera Infante y Lewis Carroll, siempre con ese sentido de humor nítidamente suyo.

La entrevista que sigue es el producto de muchas horas de conversación. Hablar con Gustavo no es fácil: es un hombre sumamente ocupado. Debido a decisiones 
editoriales y teléfonos, poder captar su atención por más de dos minutos en su oficina es una situación rara. En casa no es muy diferente. Pero Gustavo es un hombre que quiere brindar su tiempo; es consciente del papel del lector y quiere hablar de sus obras. Conversamos sobre muchos temas: la obra de él, la novela mexicana, y literatura hispanoamericana en general. Con calma y con seguridad contesta cada pregunta.

La escritora mexicana Elena Poniatowska te ha caracterizado como el James Dean de la novela en México. ¿Cómo reaccionas?

No conozco el contexto en que esto fue dicho pero calculo que James Dean para Elena, como para mi, debe significar una suerte de rebelde ante la sociedad. En Rebelde sin causa, Dean representaba un hombre que protestaba contra la familia y contra todos los elementos de la sociedad. Incluso esta película impuso la moda de vestir de los adolescentes aquí en México. Quizás Elena quiso demostrar exageradamente, diciéndolo así, que mis novelas (básicamente la primera de ellas) se escribieron como un rompimiento generacional, instaurando nuevos géneros de literatura, un nuevo género de novelar, que es precisamente la novela de jóvenes, el lenguaje de los jóvenes, la traición de la adolescencia en el núcleo urbano de México. Pero en Gazapo falta el tono político, la postura política que muchas veces se toma en la literatura mexicana, como en el caso de ciertas obras de Carlos Fuentes. ¿Como clasificarías la postura que tomas en tu primera novela?

Es también una visión política. En mi segunda novela, Obsesivos días circulares, es donde más directamente se trata de la coerción o de la represión que ejerce el núcleo en poder sobre el pueblo. Pero Gazapo es una novela política en tanto que revela la actitud de los jóvenes que no se involucran nunca en la política, que es la política dominante de la ciudad. De ahí que mi segunda novela sea evidentemente política porque la protagonista es la hija de un concesionario del gobierno que amasa una gran fortuna por su amistad con el presidente de la república. En las cuatro secciones del libro yo trato de ese tipo de corrupción en México, a través de los hijos de esa generación.

Has hablado de un rompimiento generacional, lo cual implica un establecimiento literario. ¿ Para tí todavía existe tal cosa en México?

En estos días, no. Pero hace veinte años, sí. En esa época uno tenía que escribir como Juan Rulfo o como Juan José Arreola, los cuales marcaban las dos tendencias predominantes en la literatura mexicana. Cualquier acción que rompiera con esas dos tendencias era sumamente rebelde. El primer rompimiento radical es el de Carlos Fuentes con La región más transparente. Pero los novelistas que vienen después seguían imitando una novela extranjera. En el mejor de los casos hacían la novela persiguiendo fórmulas de William Faulkner o de Cesare Pavese. No había un tono personal ni siquiera nítidamente urbano. Faltaba una picaresca contemporánea de la ciudad. Entonces Gazapo instaura este rompimiento de lenguaje, de postura ante la estructura novelística, ante el mundo. Después de Gazapo surge una corriente de literatura adolescente en la que predominan los nombres de José Augustín y Parménides García Saldaño. 
¿Que influencia piensas tá que ejerce la novela de Fuentes, La región más transparente, ahora? Me refiero más a los jóvenes que ahora están empezando a publicar.

Para los que conozco, esta novela representa un gran fresco de la ciudad mexicana, el primero que involucra posturas sociológicas, incluso una visión del México contemporáneo. Para mi generación (empezaba a escribir cuando se publicó esa novela) es un libro muy importante. Es un libro que realmente nos hizo escritores. Es un libro que le dió al escritor mexicano un lugar en la sociedad, un lugar vigente. Es el primer libro mexicano por excelencia, en que revela nuestra idiosincrasia, nuestra identidad, nuestro rostro. Es el primer libro que revela el éxito de un novelista. Es un libro que definió la vocación de muchos escritores que yo conozco. Una vez clasificaste esa novela de Fuentes como la más importante en la historia de México. ¿Todavía piensas así?

Sí, sin duda. En todos los sentidos, no sólo literariamente, sino también como una abertura de mercados para el escritor mexicano. Y es así sociológica y políticamente. No hay otra novela que marque tan claramente un cambio de época.

Acabo de leer un fragmento de tu última novela, Paseo en trapecio, que aparece en Plural como "La princesa del Palacio de Hierro". Me encanta lo que he leido. Me parece que estás trabajando con el tema del engaño otra vez.

Existe en ésta, como en todas mis obras, pero ni es el único ni el más importante tema. El engaño, el trueque, la mascarada, las falsas posturas, las dobles identidades son unos de los temas de mis libros. Gazapo se desengaña de la amistad o del amor de los padres por una serie de mentiras obsesivas. Allí me entregaba a una zona franca de mentiras que viene de Oscar Wilde y de Lewis Carroll hasta Guillermo Cabrera Infante en la novela contemporánea, en vez de esa otra literatura que va en una busca muy seria de la verdad como en el caso de Dostoievski y Tomás Mann, etc. En esta zona de mentiras yo creo que son los personajes folclóricos los que más encanto ejercen sobre mí. Me intrigan los mentirosos, o sea el merlito que vende medicinas en la calle o juguetes para engañar a los demás, los trucos, el líder sindical, el líder charro, el político que da un discurso siempre en las mismas palabras que no significan nada. Crean una riqueza de mundos verbales sin referencia con el mundo real. Implican desde luego una doble postura, un engaño, una ambigiiedad. En realidad lo que busco es la ambigüedad más que la realidad.

Mencionaste el caso de Cabrera Infante. En Tres tristes tigres vemos este mundo ambiguo y es una realidad verbal que lleva implícita una enorme cantidad de ironía.

El lenguaje, los juegos de palabras, los diferentes textos impuestos o encrustados sobre otros textos - todos estos aspectos cuestionan la realidad literaria, la posibilidad de escribir una literatura "real", o sea la novela tradicional.

En ciertos casos, los estructuralistas están descubriendo que se escriben siempre las mismas historias y que la gente ha cambiado muy poco desde que se empezó a escribir literatura. En realidad, los conflictos son los mismos. Las relaciones son las mismas. A pesar del teléfono y a pesar de los automóviles, la enajenación y "l'ennui" del hombre es igual. Yo pienso que hay realmente muy pocas novelas que inauguren 
una visión distinta del mundo, incluso la de la fantasía y de la ciencia ficción. ¿Cuáles serían los aspectos de la novela contemporánea de Hispanoamérica que consideras importantes?

Quizá lo que más caracteriza la novela contemporánea es una preocupación por el lenguaje, convirtiendo el lenguaje en el protagonista principal de la historia. Es la preocupación que se da por la ausencia de una audiencia determinada en los países latinoamericanos. Los escritores escriben para sí mismos, para los otros escritores. Sus novelas son casi codificadas. A veces son novelas sin claves, novelas basadas en el lenguaje. Otro personaje muy importante es el espacio o el tiempo en las novelas que se revelan como una constante estructural. Toda la novela hispanoamericana implica una enorme creatividad estructural en el manejo de espacios y tiempos. Quizá podía haber otra constante más que sería el tema del escritor como personaje de la obra. El escritor que habla de sí mismo. Es un tema ya anunciado por Emerson y está también en el epígrafe de Trópico de Cancer. Vendrá el tiempo en que todos los libros serán autobiografǐas. Tenemos esto en Paradiso, en Tres tristes tigres, en La revindicación del conde don Julián, en El libro de Manuel, y en Rayuela. Son todas autobiográficas .

Estoy de acuerdo contigo pero creo que hay otra tendencia más que se puede considerar. Es la de la obra que trasciende los límites tradicionalmente asignados a la novela o a la poesía. La poesía mexicana de hoy es buen ejemplo de lo que quiero decir.

Algunos escritores jóvenes como Gabriel Zaid, José Emilio Pacheco, Homero Aridjis y Marco Antonio Montes de Oca que, aunque han cateado otros géneros, en el caso de Zaid el ensayo, en el de Pacheco la novela y el cuento, son todos básicamente poetas. Y su poesía instaura condiciones muy típicas de la literatura mexicana que es una suerte de singularidad. En nuestro pais no hay géneros ni corrientes ni grupos de escritores, sino que cada escritor es terriblemente distinto de los otros. Salvador Elizondo es distinto de Augustín Yánez, y a su vez ambos son distintos de Carlos Fuentes, y son distintos de Juan Rulfo, los que son distintos de Jorge Aguilar Mora.

Es un femóneno único en que no hay corrientes literarias. Los poetas también participan de esto. Cada poeta es verdaderamente un mundo aparte.

Volvemos a hablar de la novela que estás escribiendo. Me parece que estás interesado en rescatar el lenguaje que hablaban los tipos representados por tus personajes. Recuerda mucho las obras de Manuel Puig donde él presenta el habla de cierto grupo determinado.

Mira, es una novela que describe el sexenio de un presidente de México que fue muy característico por las tantas concesiones que hizo el estado a empresarios privados. Al mismo tiempo que narro la vida de los hijos de este hombre de poder, harta de relaciones con "gangsters", prostitutas, en fin, con el bajo mundo, me esfuerzo por describir el idioma, el vocabulario, la sintaxis y las cadencias del lenguaje que se hablaba en México en esa época.

Debe ser muy difícil seguir escribiendo tu novela mientras estás tan involucrado en el trabajo de editar una revista. ¿ Piensas tú que has tardado en publicarla debido a esto? 
Como sabes, es muy difícil vivir como escritor en un país dependiente porque las novelas de uno no tienen una gran audiencia real. No se venden mucho y no dan dividendos. Los escritores caen siempre en trabajos como pueden ser la publicidad o el magisterio. Prefiero trabajos que implican mi ejercicio crítico, como son la cátedra y el periodismo. Estoy supuestamente adoctrinando al público lector, a mis alumnos, para un consumo cultural, para una lucidez mental para que se planteen y sepan plantearse mejores preguntas. Esto no lo puedo hacer yo en mis novelas. Yo creo que la novela no puede participar en la acción política. El futuro para la literatura mexicana es muy difícil de definir porque depende de muchos factores: entre otros, el mercado, la simpatía de las librerías y su promoción de los libros, etc. Pero los escritores mexicanos que conozco yo están trabajando desde la escuela, desde el periódico, en una lucha constante contra la enajenación del mundo contemporáneo. Creo que la situación del escritor dentro de la sociedad es universal. Hay muy pocos escritores tan privilegiados que se permitan el gran lujo de dedicarse totalmente a escribir sus obras. A veces es el escribir guiones de cine que les ofrece una oportunidad de ganarse la vida. William Faulkner, Carlos Fuentes y Guillermo Cabrera Infante son tres autores que lo han hecho. ¿ Has tenido experiencia en este campo?

He escrito dos guiones de cine y estoy escribiendo un tercero sobre la vida de Diego Rivera. El cine para muchos es el campo de expresión contemporáneo por excelencia. Yo siempre he sido un infatigable asistente del cine. Desde que tenía como ocho años de edad veo entre ocho y diez películas por semana. He ganado dos premios de cine en México y uno en Estados Unidos. Alguna vez haré una película pero lo que pasa es que se necesita mucho tiempo libre para hacer una película. La filmación, la dirección, la edición y la planeación de la misma implican una enorme cantidad de tiempo. $Y$ yo no tengo ese tiempo porque tengo que trabajar intensamente para poder sobrevivir.

Yale University

John P. Dwyer

NOTA :

Esta entrevista fue realizada durante un viaje a México que hizo el entrevistador como becario del Instituto de Estudios Latinoamericanos de la Universidad Yale. 
